\section{Health care a casualty in}

\section{Kenyan crisis}

$\mathrm{K}$ enya's slide into ethnic tension, anarchy and political violence has thrown the country's health sector into crisis. Drugs and other medical supplies are in short supply. Health facilities are overwhelmed by the injured and untreated. Camps for those displaced by the conflict are crowded and unsanitary. In many places, healthcare workers have abandoned their duties in fear for their lives.

Many are still hopeful that former United Nations secretary general Kofi Annan can ultimately negotiate an end to the violence that erupted along ethnic lines following the disputed December 2007 election and that has resulted in the killing of an estimated Iooo people and the displacement of 600 ooo from their homes.
Yet, even if peace is negotiated (as of $C M A$ 's Mar. 3 deadline, it had not been reached), experts fear the long-term impact on the health care system will be devastating: healthcare personnel will be lost, while efforts to contain the spread of diseases like HIV/AIDS will be hampered as patients who miss treatments develop resistance to the drugs being used to treat them.

More immediate is the challenge of treating the wounded and displaced. That challenge is particularly difficult because of the dramatic increase in the number of patients and the shortage of staff caused by insecurity, says Dr. Stephen Ochiel, head of the Kenya Medical Association.

Several doctors fled their stations as ethnic killings intensified, Ochiel says. "Our public health facilities are not only overstretched, but they are also faced by lack of drugs, medical supplies and feelings of insecurity among health workers. At the same time, ten- sion and suspicions are rife among the workers and some of the patients, which does not augur well for the provision of quality health services."

The World Health Organization (WHO) says that camps for the displaced have been overwhelmed in some areas of the country and are now struggling to deal with food and water shortages, inadequate shelter and horrific sanitation. In some camps, the toiletto-person ratio is I to 500. Diarrhea in children and acute respiratory infection have become endemic.

"In many settings, survivors have no access to even the minimum health and psychological support, leaving them vulnerable to a range of potential negative health problems, including HIV/AIDS," says WHO spokesman Fadéla Chaib.

"People are being forced to drink unsafe water, risking diarrheal diseases, infection and severe dehydration. The longer the crisis continues, the greater

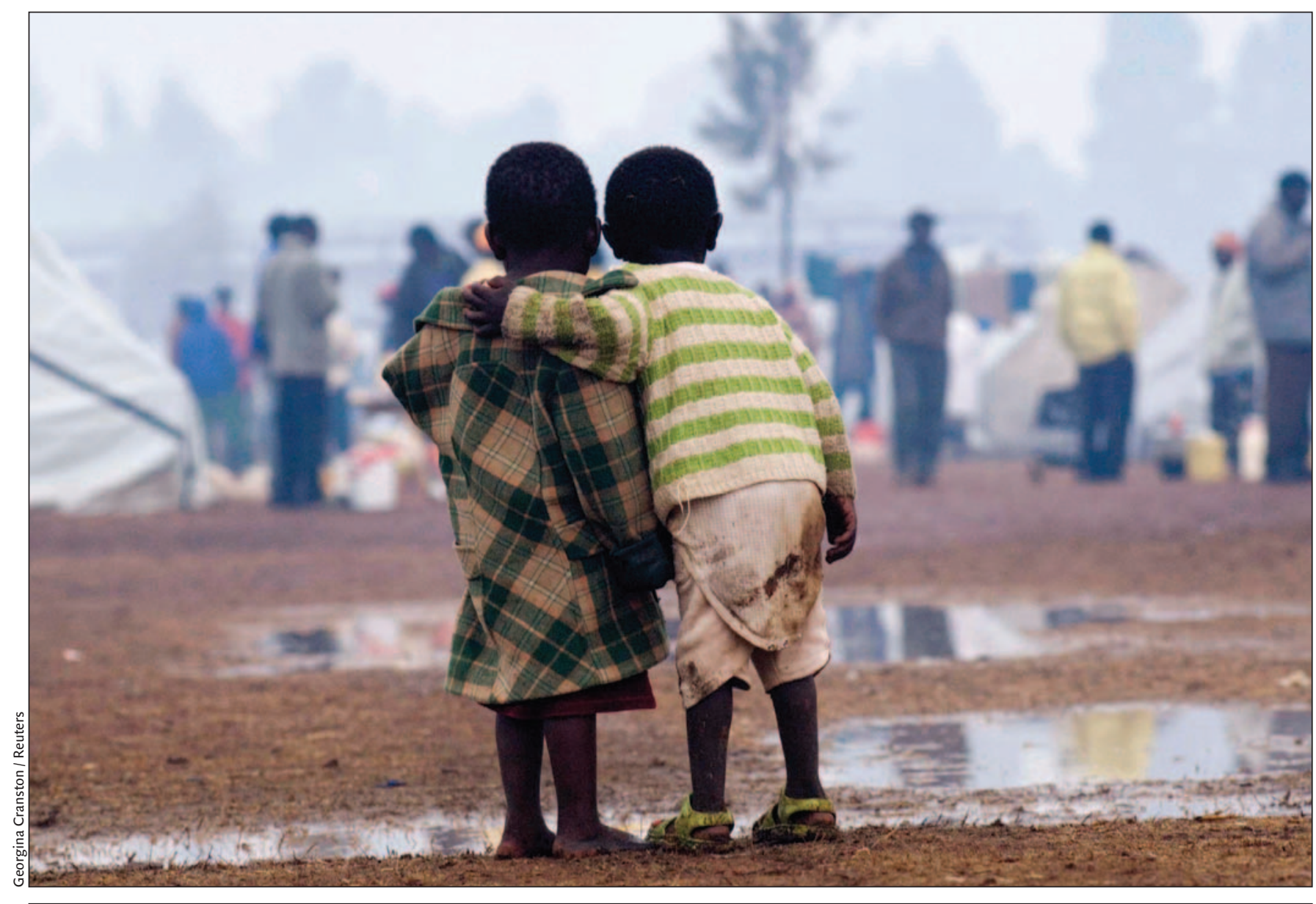

Two Kenyan children stand together as heavy rain begins to fall at a temporary shelter for 19000 displaced people in Eldoret. 
the risk to people's health," adds Wubeshet Woldermariam, country director in Kenya for the United Kingdombased nongovernmental organization Merlin Emergency Medical Relief.

But the challenges extend well beyond the camps, Chaib says. "Malaria, HIV/AIDS and TB [tuberculosis] patients cannot access their medicines regularly, while patients with asthma, hypertension and diabetes also lack access. Counseling services are not available, including for reproductive health, sexual violence or HIV/ AIDS."

The lack of access to medication has resulted in increasing number of deaths among people living with HIV/AIDS and tuberculosis.

Many can no longer access treatment, says Mette Kjaer, Kenya director for Africa Medical Relief, the largest medical nongovernmental organization in Africa. Kjaer says that at the agency's health centre in the Kibera slum of the capital Nairobi, "we've lost $60 \%$ of patients who were on antiretroviral treatment and another 30\% cent of those on TB therapy. Patients had to leave treatment behind as they fled for their lives, and are now unable to reach the health centre to replace it."

The relief agency's Communication Manager, Bob Kioko, adds that patients are staying away from the Kibera health centre for fear of being attacked, while health workers are scared of going out into the community to visit patients.

The violence has also resulted in an upsurge in reported cases of rape. "In the first 2 days of the violence, 56 people were treated for rape and admitted; there are so many other victims back in the slums who have not received any medical attention," Lucy Kiama, chief nurse at the Nairobi Women's Hospital told the UN information agency IRIN. The Kenyan police reported that 520 cases of rape occurred between late December and mid-February.

The number of rape survivors seeking treatment at the hospital has doubled, with many victims saying they knew of others who'd been raped who refused to leave their homes to seek treatment because of security concerns or fears of stigmatization.

Issues like sexual violence are being ignored, says Violet Awori, head of the
Kenyan women lawyers' association. "The government should step up security in all parts of the country to avoid further escalation of sexual and all other forms of violence, particularly in the slum areas and settlement camps where women and children remain targets for sexual abuse and assault." Wairagala Wakabi, Kampala, Uganda

DOI:I0.1503/cmaj.080289

\section{Coming soon: Med High}

$\mathrm{A}$ lberta students could be soon be studying anatomy along with their arithmetic under a government proposal to create healthcare centred high schools.

Part of a plan to swell the ranks of healthcare workers, the scheme would see a "medical" high school opened in both Calgary and Edmonton to provide students with some form of additional instruction that might prepare them for a career in health. The governing Progressive Conservatives floated the plan in the run-up to the Mar. 3, 2008, general election, in which they captured their IIth consecutive majority in a landslide.

Such a high school would help the province address its shortage of nurses, paramedics, personal care aides, doctors and every other kind of health worker as the population explodes and many workers are lured to other industries, says Health Minister Dave Hancock. "It is about finding people who are interested and giving them the opportunity to develop that interest."

But Alberta Medical Association President Dr. Darryl LaBuick isn't sold on the idea.

A lack of interest in health careers isn't the problem, LaBuick says. "Medical schools have many, many more applicants than those that get in, so from the point of view of getting people interested in medicine that is really not a problem."

LaBuick argues the focus has to be on post-secondary spaces because that is where the real training is done.

"They need to look at making spaces available for people in our community and technical colleges and universities for all of the people they want to train."

LaBuick is also concerned that the schools might ultimately affect the demographics of the health care profession in the future. "If you start to channel people too early in Calgary and Edmonton that limits the chances of people in the rural areas to get into these professions," he says, adding that might only make it that much more difficult to resolve current difficulties in attracting physicians to rural and remote areas of the province.

But Hancock contends the proposal could prove as successful as the province's registered apprentice program, which allows students to earn credits for their high school diploma and an apprenticeship in the trades at the same time. It has helped get workers into the labour-starved construction industry and a medical high school could help hospitals, long-term care facilities and ambulance providers do the same, he says.

Although the curriculum hasn't yet been established by the Calgary and Edmonton school boards, it's hoped students might be able to earn some credit toward work as a paramedic or licensed practical nurse.

Hancock is confident the boards will establish a valid program on par with those created for fine arts, or science and technology high schools. He also hopes the new schools will be able to partner with hospitals to give students a taste of a career in medicine, while at the same time providing hospitals with volunteer help.

The governing Tories poached the concept from Portland, Oregon, but if established, the schools would be the first of their kind anywhere in Canada.

The Tories also vowed on the campaign trail to increase the number of licensed physicians in the province (currently 69I8) by 225 per year, through a combination of new postsecondary entry positions and readier approvals of international medical graduates. As well, they vow to bolster the registered nursing ranks by 350 per year, and licensed practical nurses by 220 per year. — Ryan Tumilty, Edmonton, Alta.

DOI:Io.I503/cmaj.08029o 